\section{Environmental impact} assessment of aluminium production using the life cycle assessment tool and multicriteria analysis

\author{
Javad Abdollahi', Nima Emrani', Benyamin Chahkandi' ${ }^{2}$, Ali \\ Montazeri ${ }^{3}$, Reza Aghlmand ${ }^{1}$ and Mohammad Gheibi ${ }^{1 *}$
}

${ }^{1}$ Department of Civil Engineering, Ferdowsi University of Mashhad, Mashhad, Iran

${ }^{2}$ Department of Civil Engineering, University of Tehran, Iran

${ }^{3}$ Department of Civil Engineering, Shahrood University of Technology, Shahrood, Iran
ISSN: $2641-296$

DoI:
Received: 09 June, 2021

Accepted: 24 June, 2021

Published: 26 June, 2021

*Corresponding author: Mohammad Gheibi, Department of Civil Engineering, Shahrood University of Technology, Shahrood, Iran,

E-mail:mohamadgheibi@ymail.com

Keywords: Aluminum; Life cycle assessment; Air pollution control; Decision systems; Particles; Nitrogen oxides

https://www.peertechzpublications.com

Check for updates

\title{
Abstract
}

Air pollution is one of the most important problems of urban life. Since a large proportion of airborne pollutants originate from industry, it is important to address emission removal systems. One of the growing industries is the production of aluminum, which requires attention and planning since emits dangerous pollutants such as particulate matter, $\mathrm{SO}_{2}, \mathrm{NOx}$, dioxins, furans, mercury chloride, and fluorine compounds. The present study investigates the production life cycle of this metal and analyzes the production of gaseous pollutants and particles in different production units. Large amount of pollution is produced in the alumina production and the aluminum electrolysis units, which in the best case, for the production of one ton of final aluminum, Emit 1.07, 4.73, and 1.32 kg of particulate pollutants, sulfur dioxide, and nitrogen dioxide respectively. In the next step, in the search of the optimal system for controlling particulate pollutants, SO2, NOx caused by aluminum production, by reviewing the research background and related articles and books, ranked these systems using ELECTRE, TOPSIS and SAW methods. Sedimentation chamber, internal separators, cyclones, fabric filters, electrostatic precipitators, and wet collectors in particle removal and condensation, absorption, adsorption, incineration, and wet washing in $\mathrm{SO}_{2}$ and $\mathrm{NO}_{x}$ removal were reviewed and compared. The results show the superiority of cyclones in particle removal, wet washing system for removing $\mathrm{SO}_{2}$, and adsorption for removing $\mathrm{NO}_{x}$.

\section{Introduction}

In advanced societies, aluminum is the most widely used element after steel and its derivatives, among different industries; and after steel, aluminum is the most highly produced metal and the most produced non-ferrous metal. Features such as low weight, corrosion resistance, and high ductility have led to a greater tendency to use aluminum in the aerospace, automotive, transportation, construction, beverage, and electrical industries [1-4]. Based on assessments in 2005 , it was predicted that by the end of 2050 , the demand for aluminum in various industrial applications will increase 2.6 to 3.5 times [5]. According to the statistics announced in 2013 , China by $42.9 \%$ aluminum and $41.7 \%$ alumina is the largest producer in the world [6]. The production process in various industries requires a huge supply of energy. While this energy supply leads to the emission of pollutants such as $\mathrm{CO}$, $\mathrm{SO}_{2}, \mathrm{NO}_{2}, \mathrm{O}_{3}, \mathrm{PM}_{10}$, and $\mathrm{PM}_{2.5}$. Studies and evaluations show that most of the energy consumption of industries is related to fundamentals such as steel, cement, paper, aluminum, and plastics [5].

Among the mentioned industries, aluminum and steel have the highest energy consumption and consequently the production of carbon pollution. According to field research conducted by scientific authorities in 2012, 66 MJ of energy was required to produce one kilogram of primary aluminum [6]. Therefore, saving energy and reducing pollutants is a 
key element in the sustainable development of the aluminum industry [1]. Aluminum production from bauxite mines needs more energy rather than other metals, which leads to large emissions of greenhouse gases [7]. On a global scale, almost one percent of greenhouse gases is the result of aluminum production [8]. It should also be noted that during the aluminum production process, hazardous compounds such as fluorine, sulfur dioxide, hydrogen sulfide, and polycyclic aromatic hydrocarbons are released into the air, leading to many chronic and acute epidemiological effects on human health [9-11]. Two successive process chains including preparing alumina (aluminum oxide) from bauxite rock and aluminum from raw alumina are performed to produce aluminum. These processes require a lot of energy, which is a huge potential for emissions [12]. Melting steps and processes associated with primary production (including mining, purifying, and anode production for refining) account for $90 \%$ of all contaminants [13].

The most important source of pollution is indirect pollutants, which often occur during the process of generating electricity and account for $65 \%$ of pollution, another $18 \%$ is related to the internal production process of factories and the remaining $17 \%$ is emitted by burning fossil fuels [14]. To determine the amount of emitted pollutants in the production process of aluminum, a systematic approach and modern technologies shall be used [2]. Life Cycle Assessment (LCA) is a top-down approach to determine the consumption or production of environmental factors over the life period of a single product, which performs measurements by the time of beginning until that product is dumped $[2,12]$. During a study in Canada, Norgate and Rankin (2001) analyzed the emission of greenhouse gases generated by the aluminum production process using a life cycle assessment method [15]. Also, Reginald, et al. (2005) conducted research on the primary aluminum supply cycle and the resulting contaminants through the LCA method [12]. In another study, Hong et al. (2012) evaluated the production of aluminum and silicon alloys in China using an economic and environmental life cycle [16]. Ingarao, et al. (2016) studied the energy consumption and $\mathrm{CO}_{2}$ production of Aluminum windows of high-speed trains manufacturing process using the LCA method [17]. Also, Paraskevas, et al. (2016) analyzed the environmental impacts of primary aluminum production in different countries using the life cycle assessment method [14]. In this study, due to the little attention paid to aluminum-related contaminants in industry in previous studies, it is necessary to conduct the present study with a different approach/framework. The present study in the first step intends to (i) determine the amount of air pollution generated by aluminum production using the LCA method and in the next step; (ii) prioritize different treatment methods of particulate matters, nitrogen oxides, and sulfur dioxide in terms of environmental, economic and engineering using ELECTRE (ELimination Et Choix Traduisant la REalité), Entropy and SAW (Simple Additive Weighting) techniques.

\section{Materials and methods}

This research was conducted in two general phases including environmental assessments and prioritization of control systems. In the first phase, the life cycle assessment was used to evaluate the amount of air pollution caused by aluminum production. In the second phase, different methods of controlling and treating air pollution were prioritized using the ELECTRE decision-making system and considering environmental, economic, environmental, and engineering indicators.

\section{Life cycle assessment}

Life cycle assessment is a scientific and systematic framework for estimating the environmental impact of a product. This is a new and underdeveloped method that was first used for energy in the 1960s and then in the 1970s to prevent pollution [18]. In general, the life cycle of a single product includes the extraction and processing of raw materials, energy supply, manufacturing, use, recycling, and final disposal. There are different approaches in evaluating the life cycle of a product, cradle to grave, cradle to gate, cradle to cradle, gate to gate. Also, in the cradle to grave approach, the product is under evaluation from the extraction of raw material (cradle) to its final disposal (grave). In the cradle to gate approach, the evaluation starts with extraction until right before the transfer to the consumer. On the other hand, the cradle to cradle approach is a special form of cradle to grave; except that instead of the disposal stage, the recycling stage takes place. Also, in the gate-to-gate method, just parts of the production chain will be examined $[18,19]$. The present study intends to evaluate the life cycle of aluminum from the bauxite extraction stage (cradle) to the primary aluminum production stage (gate). The primary aluminum production process includes bauxite extraction, alumina refining, aluminum electrolysis, anode production, and aluminum ingot casting. It should be noted that the stages of using the final product and also the recycling stage have not been considered in this study. The primary aluminum supply chain diagram is depicted in Figure 1. Furthermore, the aluminum production process and all data in this study are taken from the World Aluminum Organization data in 2010.

\section{Gaseous pollutants separation methods}

Knowing the purpose of particle removal in search of a suitable method to control pollution, different methods and techniques shall be examined and evaluated. The most common particle removal techniques are as follows.

Sedimentation chamber: The sedimentation chamber consists essentially of a chamber, in which the velocity of the particle is reduced to such an extent that it settles due to gravity. One of the advantages of this method is that the required energy to perform this process is provided by gravity and of course the energy costs are very low. The application of this method is limited to the removal of particles with a diameter greater than 4 microns. The most common type of sedimentation chamber is a relatively long box that is placed horizontally. The gas enters the chamber from one side and leaves from the other side.

Internal separators: In addition to gravity, these units use another way to improve separation and collection. This happens by changing the direction of gas flow velocity to create an additional sedimentation rate for the particles. This 


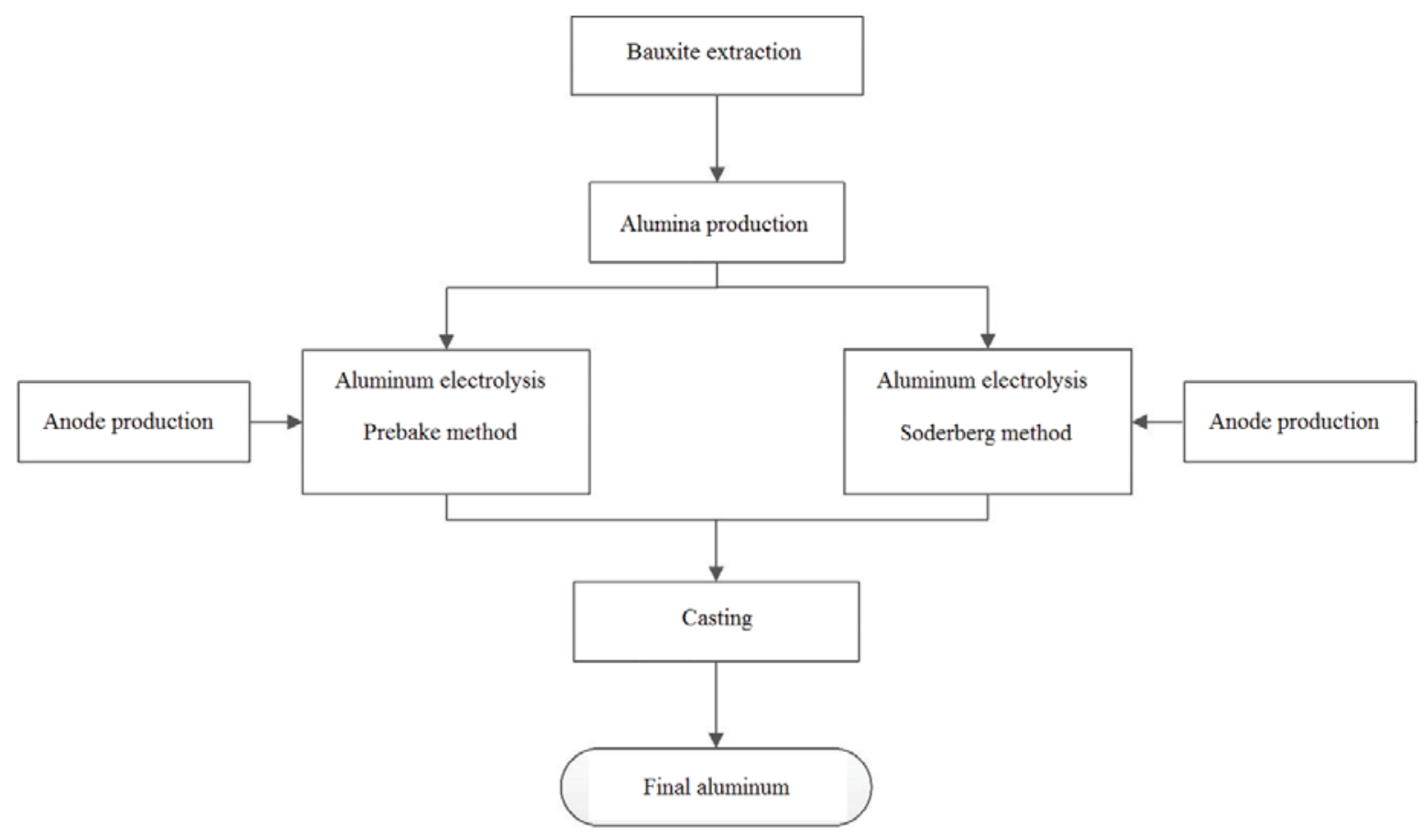

Figure 1: The aluminum production process according to the World Aluminum Organization report 2010.

method works best for small particles with a diameter of 10 to 20 microns.

Cyclones: Cyclones are another powerful particle removal method, which occurs based on the centrifugation principle. Here, particles (which have a higher weight and density) are thrown towards the tank walls and then slip into a collector. Cyclones are the most widely used dust separators due to the high percentage of separation in these units. Generally, cyclones are used when the particles are large and high concentrated and also when there is no need for high efficiency.

Fabric filters: Filtration is one of the most widespread and oldest suspended particle separating methods. A filter is a compact porous medium made of fibrous or granular material through which gas passes and suspended particles remain among the filter, depending on the application location and the expected efficiency, different types of filters are available. In recent years, deformed filters called cartridges have found their place on the market, which can be cleaned in different ways such as pulse jets, etc. They range from paper to chemical and heat resistant. Fabric filters generally show a high efficiency even when removing micron-sized particles. This system is often preferred when recycling valuable dry materials is of a high priority. However, the compulsion to keep the gas at a higher temperature than the dew point is one of the limitations of this method. Usually, if the gas temperature and volume are relatively low, this method is more applicable.

Electrostatic precipitators: In this method which is one of the most important industrial cleaning devices, particles are charged and absorbed by their opposite poles. This method first was invented in 1910 by F.G. Cottrell. This method is capable of accepting a large volume of gas, high particle separation efficiency for sub-micron particles, low energy consumption, and the possibility of separating particles from high-temperature gases also, the pressure drop is about 0.1 to 0.5 inches of water and the efficiency is 90 to $99 \%$. Due to the advantages of this method, it is possible to use them in different industries, especially power plants. The energy used in these control devices depends only on the particles themselves and not on the gas flow which is not accessible through other refining methods. Electrostatic precipitators which are common in tube and plate types usually have very high efficiencies at removing micron-sized particles. They are a valuable option if the gas volume entering the pollution control unit is large or the purpose is to collect precious materials.

Wet scrubbers: These pollutant control systems are used to remove both particulate matter and gases. In these systems, a liquid, usually water, is used to trap dust particles or increase the size of aerosols. Liquid and solid particles are effectively separated in the range of 0.1 to 20 microns which requires a proper liquid contact. Accordingly, there are three types of wet scrubbers, including spray chamber, cyclone tower, and venturi wet scrubber. Wet collectors are generally used when particles are fine and relatively high efficiency is required simultaneously. They work best if the gas needs to be cooled and the moisture does not cause problems. Furthermore, if the system aims to remove particles and combustible gases simultaneously, wet collectors are one of the best treating options.

Particle control devices should be designed in such a way that they can remove $10 \%$ higher than the load leaving the industrial unit. Various systems have been designed to remove gases and vapors (including sulfur oxides, nitrogen oxides, toxic mercury vapors, and other gaseous pollutants). The basic performance of these systems is classified into four groups: 
Condensation: In this process, gas or steam is liquefied, which is done either by decreasing the temperature or increasing the pressure. Temperature drops are usually more common due to their low cost. Condensers are simple and inexpensive devices that use water or air to cool and compress air. The efficiency of these devices in removing pollutants is very low and they are mostly used as pre-treatment. Using them before sorbents and incinerators are convenient because they reduce the gas volume and refining costs. There are two types of condensers The first type is contactual (direct contact), in which the condenser of the cooling and condensing environment is combined. The second type is surface condensers (indirect contact) that separate the cooling medium and the condensed steam.

Adsorption: The concentration of a substance on the surface of a solid or liquid is called adsorption. Adsorbents such as activated carbon and activated alumina, silica gel, and molecular filter are common in the industry. The difference between absorption and adsorption is that the adsorbent can be both solid and liquid, the absorbent is only liquid and the absorbate is distributed throughout the liquid but the adsorbate remains only on the surface. Separation of adsorbed and adsorbent from each other is usually possible by increasing the temperature and decreasing the pressure.

Absorption: This process, as mentioned earlier, involves a complete contact of the gas mixture with a liquid to dissolve one or more gas components which is the main point in the designing process. These systems are available in two types of filled columns (packed) and plates.

Incineration: Incineration is often used to control organic matter release. At high temperatures and suitable retention time, all hydrocarbons can be converted into carbon dioxide and water which is also used to remove hazardous and toxic gases. If the combustion process of organic compounds remains incomplete, it will form aldehydes and organic acids that can create even more pollution. For complete combustion, sufficient temperature to ignite, adequate mixing of air, fuel, and waste, proper retention time, etc. must be met. Although most organic compounds burn at 590 to 650 degrees Celsius, most combustion plants operate at temperatures of 1000 to 1200 degrees Celsius. The combustion process used to control the emission is called after burning.

There are various methods (e.g., using low-sulfur fuels and natural gas, injection of limestone in both dry and wet forms, catalytic oxidation with vanadium pentoxide, and washing with alkaline sodium) to control sulfur oxides. it is also possible to implement Combustion with low excess air to control nitrogen oxides as an additional solution. Two-stage combustion, flue gas recirculation, burner design change, using wet washers and catalysts are other ways to control nitrogen oxide pollutants.

\section{Decision-making methods}

Electre: In this method, all options are evaluated using non-ranking comparison which eliminates ineffective options. All stages are based on a concordance and discordance set therefore it is called "inconsistency analysis". First, by
Equation 1, the decision matrix becomes a scale less matrix.

$$
n_{i j}=\frac{r_{i j}}{\sqrt{\sum_{i=1}^{n} r_{i j}^{2}}}
$$

Later on, the concordance matrix of $\mathrm{S}_{\mathrm{kl}}$ and the discordance matrix of $\mathrm{D}_{\mathrm{kl}}$ will be calculated using Equation 2, then the coefficient criterion between $A_{k}$ and $A_{1}$ will be estimated based on Equation 3. Meanwhile, the higher the value of parameter $\mathrm{I}_{\mathrm{kl}}$; Indicates the more appropriateness of $\mathrm{A}_{\mathrm{k}}$ 's assessment concerning $\mathrm{A}_{1}$.

$$
\begin{aligned}
& S_{k l}=\left\{j \mid r_{k j} \geq r_{l j}\right\} \\
& D_{k l}=\left\{j \mid r_{k j} \geq r_{l j}\right\}
\end{aligned}
$$

$$
I_{k l}=\sum_{J \in S_{k l}} w_{j} \quad ; \quad \sum_{j=1}^{n} w_{j}=1
$$

The discordance matrix is formed by Equation 4 and the effective concordance matrix is formed based on the minimum threshold of Boolean $\mathrm{F}$ and $\mathrm{G}$ matrices with zero and one element, which are described in Equation 5.

$$
\begin{array}{ll}
N I_{k l}=\frac{\max _{j \in D_{k l}}\left|V_{k j}-V_{l j}\right|}{\max _{j \in J}\left|V_{k j}-V_{l j}\right|} & \\
\overline{N I}=\sum_{k=1}^{m} \sum_{l=1}^{m} N I_{k, l} / m(m-1) & \bar{I}=\sum_{k=1}^{m} \sum_{l=1}^{m} I_{k, l} / m(m-1) \\
\text { if }: N I_{k, l} \geq \overline{N I} \longrightarrow g_{k, l}=1 & \text { if }: I_{k, l} \geq \bar{I} \longrightarrow f_{k, l}=1 \\
\text { if }: N I_{k, l}<\overline{N I} \longrightarrow g_{k, l}=0 & \text { if }: I_{k, l}<\bar{I} \longrightarrow f_{k, l}=0
\end{array}
$$

Finally, the general matrix $\mathrm{h}$, which represents the order of relative preferences of the options, will be calculated using Equation 6.

$$
h_{k, l}=f_{k, l} \cdot g_{k, l}
$$

\section{Topsis analysis system}

TOPSIS (Technique for Order Preference by Similarity to Ideal Solution) means ways of preferences based on similarities to the ideal solution. This model was proposed by Huang and Eun in 1981 which evaluates $\mathrm{m}$ options by $\mathrm{n}$ indicators. The basic logic of this model defines the ideal (positive) solution and the negative ideal solution. The ideal (positive) solution increases the profit and decreases the cost criterion. The optimal option has the shortest distance from the ideal solution and simultaneously the farthest distance from the negative ideal solution. In other words, in ranking the options by the TOPSIS method, options having the most similarity with the ideal solution get a higher rank. 


\section{The SAW method}

The SAW method is the simplest way of weighting and prioritizing parameters. In this method, in addition to the weight of each comparative parameter, an importance coefficient as Equation 7 is applied which makes it a reliable and simple method.

$$
W_{i}=\sum_{j=1}^{n} W_{j} * r_{i j} \quad i=1,2,3,4,5
$$

\section{Results and discussion}

The amount of emission in different units of the aluminum production process

According to a study conducted by the International Aluminum Institute, the amount of emission during the production process of this metal in various units is presented in Table 1 that the most important of which are carbon dioxide, sulfur, sulfur dioxide, nitrogen dioxide, compounds containing mercury and its vapors, and halogenated particles containing fluorine.

These Emissions, if not properly managed and controlled, can lead to serious pollution in cities adjacent to industry. Concentrations of these pollutants in urban environments, if they reach above the standard, endanger citizens at different levels. In addition to the adverse effects on plants, buildings, and animals, they pose a serious threat to human health.

Emissions in the aluminum production process in different units has different amounts and concentrations. Figures 2 to 5 show the concentration of particulate matter, carbon dioxide, sulfur dioxide, and nitrogen oxides in different units of the aluminum production process. Most particulate matter

Table 1: Production of particles and gaseous pollutants derived from aluminum production for each unit.

\begin{tabular}{|c|c|c|c|c|c|c|c|}
\hline \multirow{3}{*}{ Pollutants } & \multirow{3}{*}{ unit } & \multicolumn{5}{|c|}{ Production Unit } & \multirow[b]{2}{*}{ Total } \\
\hline & & Bauxite & Alumina & Anode paste & Electrolysis & Casting & \\
\hline & & 5.571 ton & 1.934 ton & 0.439 ton & 1 ton of Molten Aluminum & 1-ton ingot & 1-ton ingot \\
\hline Particulate Matters & $\mathrm{kg} / \mathrm{ton}$ & 0.94 & 1.07 & 0.086 & 2.55 & 0.037 & 4.68 \\
\hline $\mathrm{CO}_{2}$ & $\mathrm{~kg} / \mathrm{ton}$ & 7.71 & 1345.38 & 171.03 & 1537.79 & 54.03 & 3115.94 \\
\hline $\mathrm{SO}_{2}$ & $\mathrm{~kg} / \mathrm{ton}$ & - & 4.73 & 1.71 & 14.91 & 0.11 & 21.46 \\
\hline $\mathrm{NO}_{2}$ & $\mathrm{~kg} / \mathrm{ton}$ & - & 1.32 & 0.3 & 0.25 & 0.072 & 1.94 \\
\hline $\mathrm{Hg}$ & $\mathrm{kg} / \mathrm{ton}$ & - & 0.47 & - & - & - & 0.47 \\
\hline Particulate Fluoride & $\mathrm{kg} / \mathrm{ton}$ & - & - & 0.00085 & 0.55 & - & $0.55 c$ \\
\hline Gaseous Fluoride & $\mathrm{kg} / \mathrm{ton}$ & - & - & 0.0029 & 0.57 & - & 0.57 \\
\hline Total polycyclic Aromatic Hydrocarbons & $\mathrm{kg} / \mathrm{ton}$ & - & - & 0.02 & 0.054 & - & 0.074 \\
\hline Benzo(a)Pyrene & $\mathrm{kg} / \mathrm{ton}$ & - & - & 0.084 & 0.74 & - & 0.82 \\
\hline Tetrafluoromethane & $\mathrm{kg} / \mathrm{ton}$ & - & - & - & 0.056 & - & 0.06 \\
\hline Hexafluoroethane & $\mathrm{kg} / \mathrm{ton}$ & - & - & - & 0.0075 & - & 0.01 \\
\hline Hydrogen Chloride & $\mathrm{kg} / \mathrm{ton}$ & - & - & - & - & 0.024 & 0.024 \\
\hline Dioxin/furans & $\mathrm{kg} / \mathrm{ton}$ & - & - & - & - & 1.32E-09 & 1.32E-09 \\
\hline
\end{tabular}

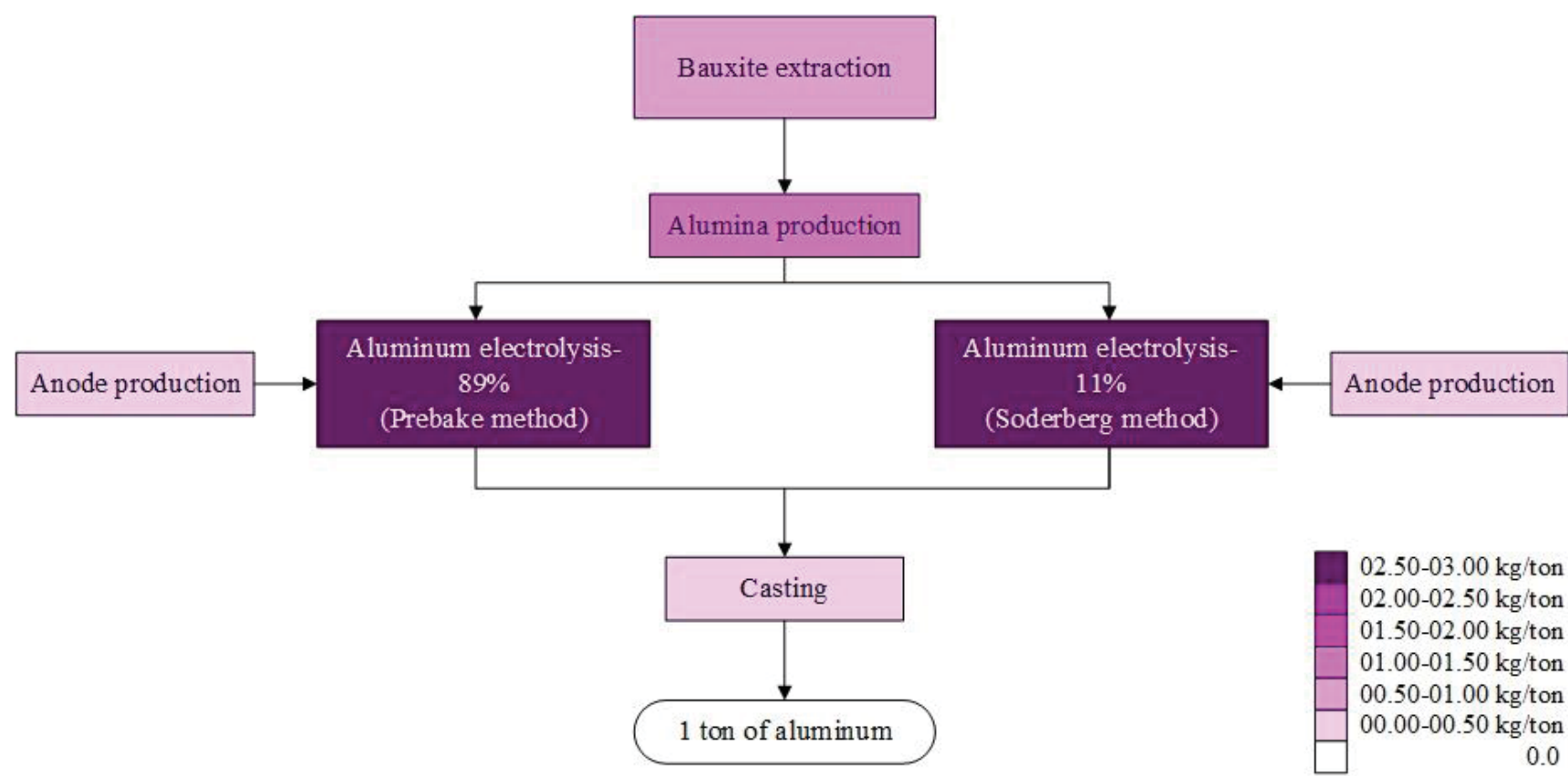




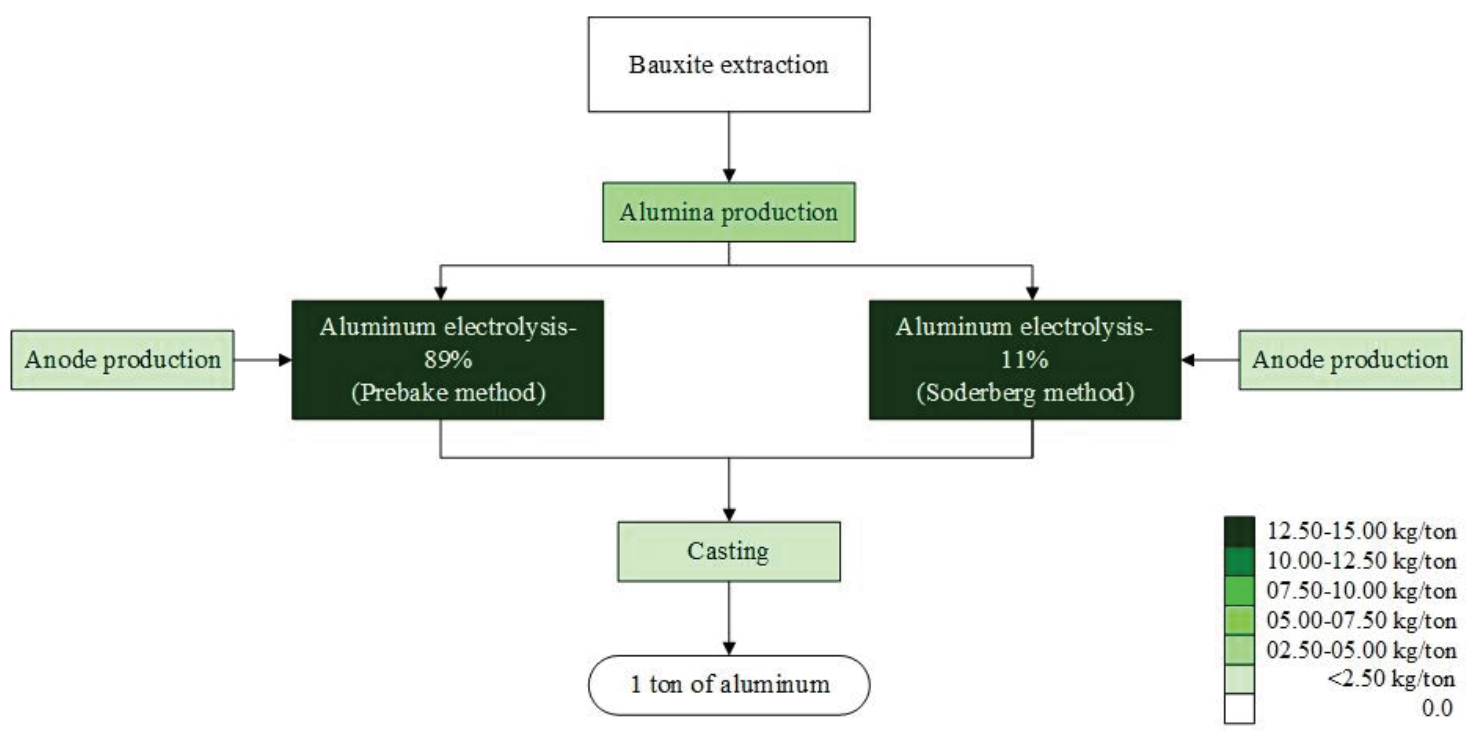

Figure 3: Amount of $\mathrm{SO}_{2}$ emitted from different units of an aluminum production process per one ton of final aluminum.

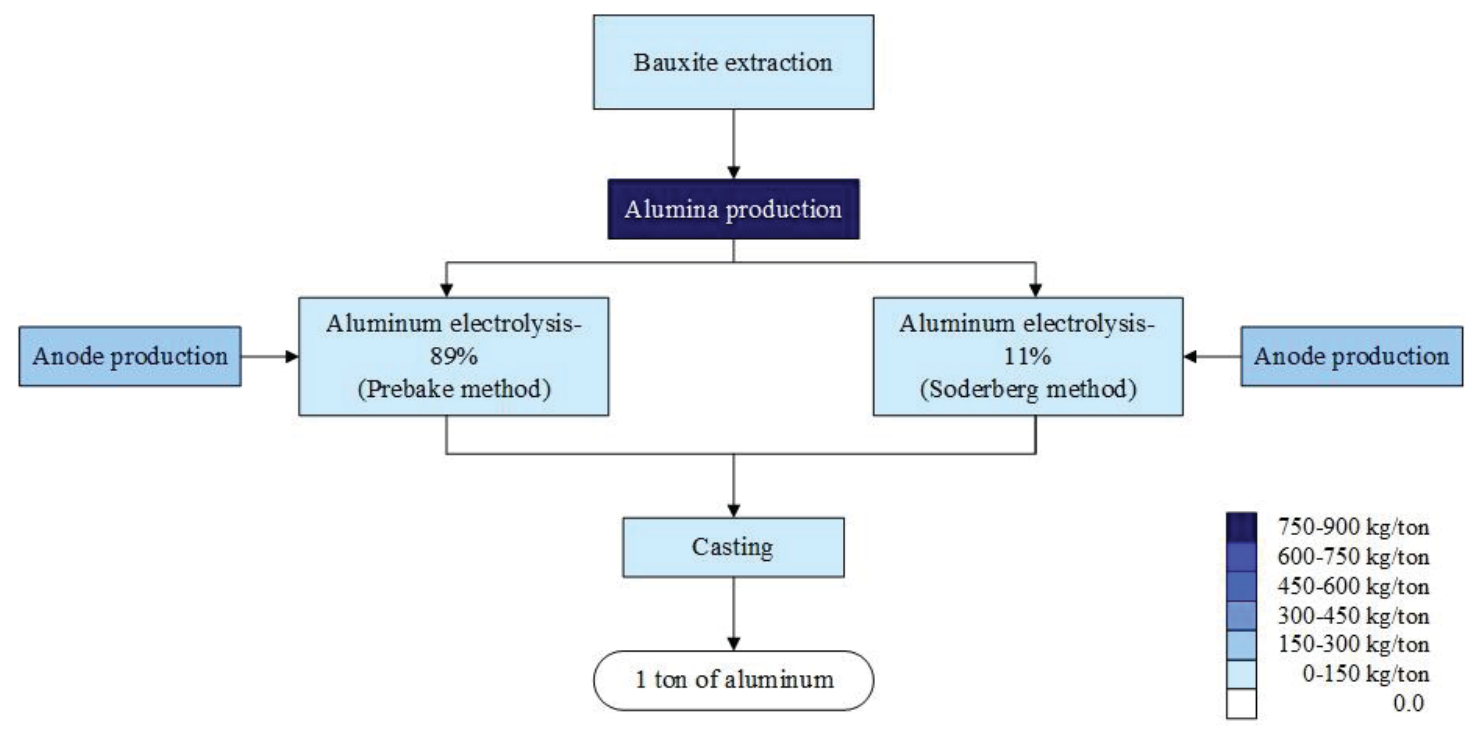

Figure 4: Amount of $\mathrm{CO} 2$ emitted from different units of an aluminum production process per one ton of final aluminum.

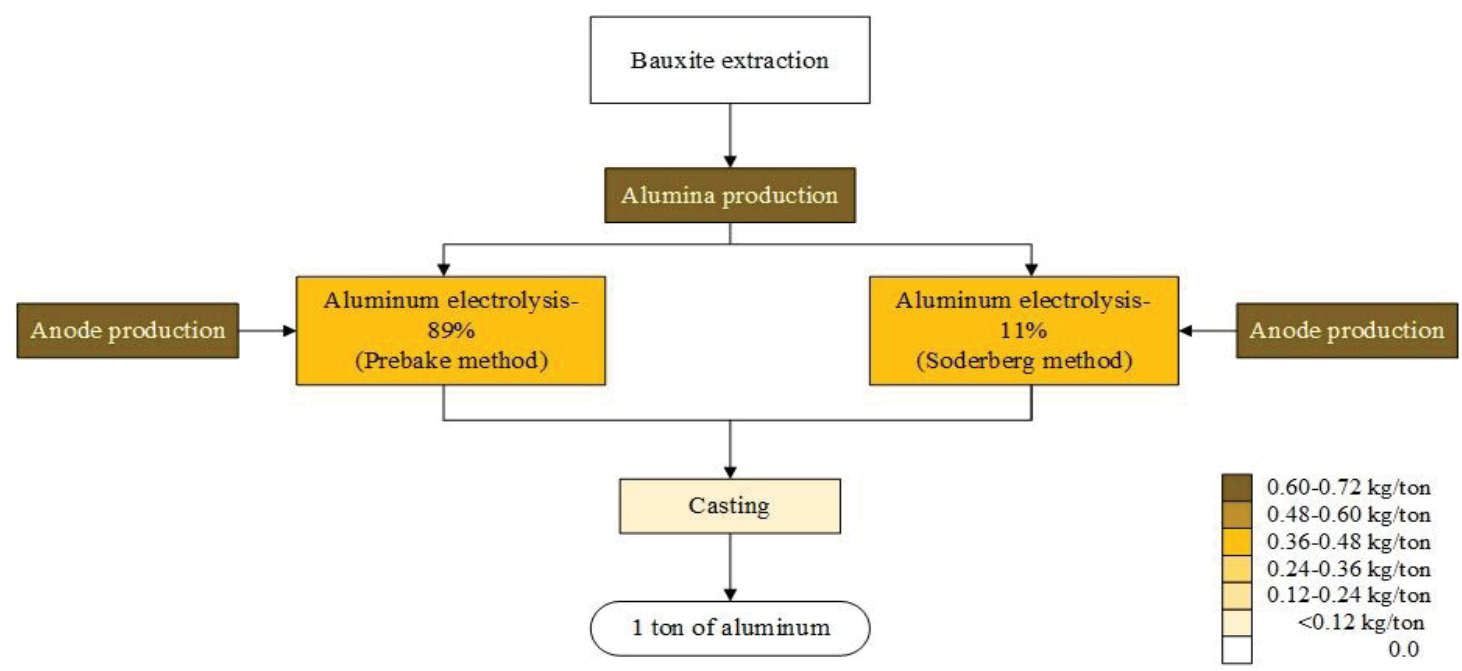

Figure 5: Amount of $\mathrm{NO}_{x}$ emitted from different units of an aluminum production process per one ton of final aluminum.

Citation: Abdollahi J, Emrani N, Chahkandi B, Montazeri A, Gheibi M, at al.(2021) Environmental impact assessment of aluminium production using the life cycle assessment tool and multi-criteria analysis. Ann Environ Sci Toxicol 5(1): 059-066. DOI: https://dx.doi.org/10.17352/aest.000038 
production occurs during the aluminum electrolysis. This also happens in the production of sulfur dioxide, and this unit has the highest concentration of sulfur pollution. However, this unit has a much smaller share in the production of carbon dioxide and nitrogen oxides and the highest production of these two pollutants occurs in the alumina production unit. on the other hand, the anode production unit also has a relatively equal share in the production of nitrogen oxides. As it turns out, the bauxite production unit has no role in releasing sulfur dioxide and nitrogen oxides.

Other toxic pollutants produced during the aluminum extraction process are such as dioxins, furans, hexafluoroethane, tetrafluoromethane, fluoride (gaseous and particulate) polycyclic aromatic hydrocarbons (PAH), mercury, and benzopyrene. These pollutants, despite their lower concentrations than the indicator pollutants (carbon dioxide, particles, etc.), need special attention because they have much higher degrees of toxicity and researches has proved the carcinogenicity of polycyclic aromatic hydrocarbons. The concentration of these contaminants also varies in different process units (Figures 6 and 7). In general, the electrolysis unit has the largest share in generating pollution. In this case, the study of figures shows that the bauxite unit does not affect the production of pollutants.

\section{Prioritizing air pollution control methods}

As mentioned before, controlling air pollution is inevitable, and given the significance of pollutants such as particles, sulfur dioxide, and nitrogen oxides, they are top priority in controlling management, which includes 6 main methods of implementation (sedimentation chamber, internal separators, cyclones, fabric filters, electrostatic precipitators, and wet collectors). Aiming for the evaluation of different pollution control options in terms of environmental, economic, and engineering, the latest researches and books considering air pollution control were analyzed. The results indicate the weights as in Table 2 for all options.

There are five general methods to remove gaseous pollutants (including condensation, absorption, adsorption, incineration, and wet washing). Thus, the value of different gas removal options for sulfur dioxide and nitrogen oxides follows in Table 3.

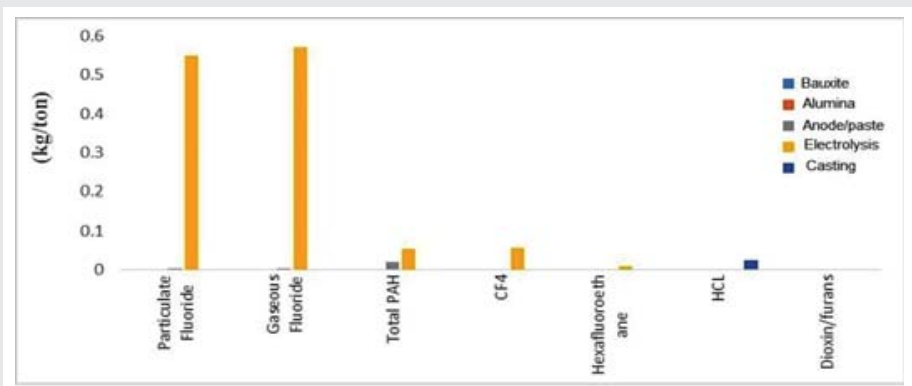

Figure 6: Emissions of dioxins, furans, Hexafluoroethane, tetra fluorocarbons, aromatic hydrocarbons (PAH), and fluorine (gaseous and particulate) in different steps of the aluminum production process.

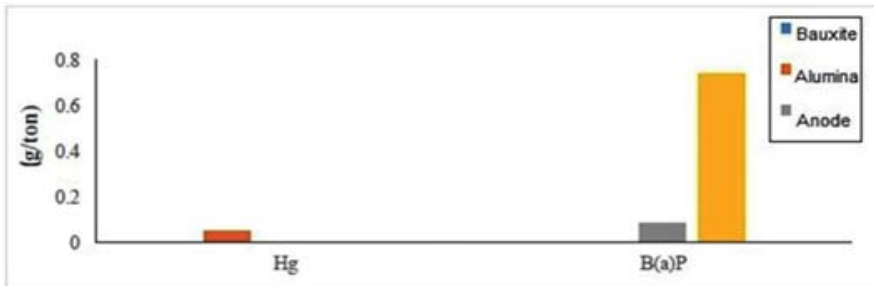

Figure 7: Emission of mercury and benzopyrene in different steps of the aluminum production process.

Table 2: Value of different particulate control options in terms of environmental, economic, and technical.

\begin{tabular}{|c|c|c|c|c|c|c|}
\hline & $\begin{array}{c}\text { Sedimen- } \\
\text { tation } \\
\text { chamber }\end{array}$ & $\begin{array}{c}\text { Internal } \\
\text { separators }\end{array}$ & Cyclones & $\begin{array}{c}\text { Fabric } \\
\text { filters }\end{array}$ & $\begin{array}{c}\text { Electrostatic } \\
\text { precipitator }\end{array}$ & $\begin{array}{c}\text { Wet } \\
\text { collectors }\end{array}$ \\
\hline Environmental & 3 & 5 & 7 & 9 & 8 & 8 \\
\hline Economic & 1 & 4 & 3 & 7 & 8 & 6 \\
\hline Technical & 9 & 8 & 6 & 6 & 5 & 7 \\
\hline
\end{tabular}

Table 3: Value of different $\mathrm{SO}_{2}$ and $\mathrm{NO}_{x}$ control options in terms of environmental, economic, and technical.

\begin{tabular}{|c|c|c|c|c|c|c|}
\hline & & Condensation & Adsorption & Absorption & Incineration & $\begin{array}{c}\text { Wet } \\
\text { washing }\end{array}$ \\
\hline \multirow{3}{*}{$\mathrm{SO} 2$} & Environmental & 5 & 7 & 8 & 6 & 8 \\
\hline & Economic & 6 & 4 & 5 & 9 & 4 \\
\hline & Technical & 6 & 7 & 7 & 5 & 7 \\
\hline \multirow{3}{*}{ NOx } & Environmental & 6 & 8 & 7 & 5 & 8 \\
\hline & Economic & 5 & 4 & 4 & 9 & 4 \\
\hline & Technical & 6 & 7 & 8 & 5 & 8 \\
\hline
\end{tabular}

The analysis of the data extracted from previous studies was performed using SAW, TOPSIS, and ELECTRE methods. Thus, the various solutions expressed for the control of particles and gases were separately prioritized in terms of environmental, economic, and technical (with equal weights). Results are presented in Figures 8 to 10.

\section{Conclusion}

The most critical pollutants emitted by these units are particulate matter, $\mathrm{CO}_{2}, \mathrm{SO}_{2}, \mathrm{NO}_{2}$, mercury compounds, and halogenated fluorine particles. Most of the emission is produced by the alumina and aluminum electrolysis units which create $1.07,4.73$, and $1.32 \mathrm{Kg}$ of particulate matter, sulfur dioxide, and nitrogen dioxide respectively for producing 1 ton of aluminum. Then, using ELECTRE, TOPSIS, and SAW methods different ways of controlling pollutants such as particles, $\mathrm{SO}_{2}$, and $\mathrm{NOx}$ derived from producing aluminum have been prioritized to find the optimum solution.

The basic criterion for prioritizing refining methods in this study was the superiority of employment in the aluminum production process. The cyclones and sedimentation chamber has been preferred over other methods and also the cyclone system has obtained more votes than the sedimentation chamber for controlling particles. The best method for controlling sulfur dioxide is the air washer system, which is followed by the adsorption method. Evaluation of nitrogen oxide control methods also resulted in the superiority of absorption and adsorption methods which was associated with the relative superiority of adsorption. 


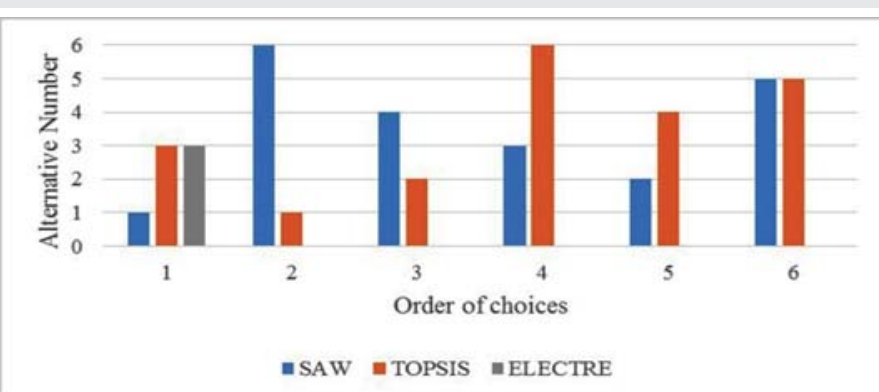

Figure 8: Application prioritization of pollution control systems (1. sedimentation chamber; 2 . internal separators; 3 . Cyclones; 4 . fabric filters; 5 . electrostatic precipitators; and, 6 . wet collectors, respectively) for particle control, derived from ELECTRE, TOPSIS, and SAW classification methods.

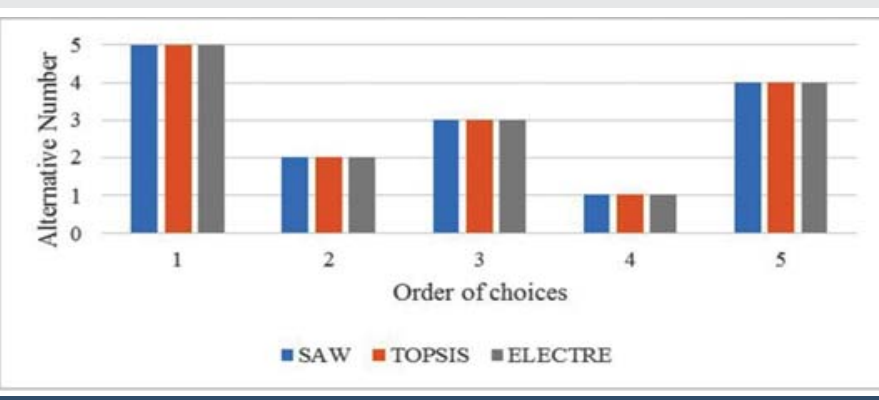

Figure 9: Application prioritization of pollution control systems (1. Condensation; 2. Adsorption; 3. Absorption; 4. Incineration; and, 5. wet washing respectively) for $\mathrm{SO}_{2}$ control, derived from ELECTRE, TOPSIS, and SAW classification methods.

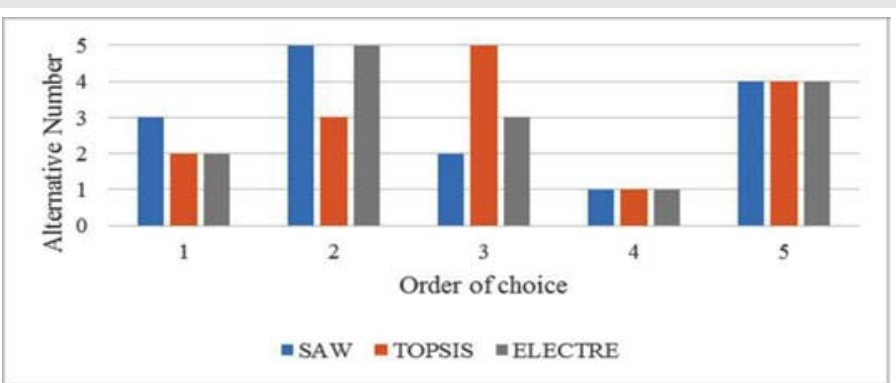

Figure 10: Application prioritization of pollution control systems (1. Condensation; 2. Adsorption; 3. Absorption; 4. Incineration; and, 5. wet washing respectively) for NOx control, derived from ELECTRE, TOPSIS, and SAW classification methods.c

\section{References}

1. Liu G, Müller DB (2012) Addressing sustainability in the aluminum industry: a critical review of life cycle assessments. Journal of Cleaner Production 35 108-117. Link: https://bit.ly/2SudwRU

2. Zhang $Y$, Sun $M$, Hong J, Han X, He J, et al. (2016) Environmental footprint of aluminum production in China. Journal of Cleaner Production 133: 1242-1251. Link: https://bit.ly/3qo9abr

3. Australian Aluminum Council. Aluminum and the Australian Economy. 2000.

4. Brough D, Jouhara $H(2020)$ The aluminium industry: A review on state-of the-art technologies, environmental impacts and possibilities for waste heat recovery. International Journal of Thermofluids 1: 100007. Link:
https://bit.ly/2U1zY58

5. Gutowski TG, Sahni S, Allwood JM, Ashby MF, Worrell E (2013) The energy required to produce materials: constraints on energy-intensity improvements, parameters of demand. Philosophical Transactions of the Royal Society A: Mathematical, Physical and Engineering Sciences 371: 20120003. Link: https://bit.ly/3wX04or

6. The International Aluminium Institute, 2015; Link: https://bit.ly/35PapH0

7. Norgate TE, Jahanshahi S, Rankin WJ (2007) Assessing the environmenta impact of metal production processes. Journal of Cleaner Production 15: 838848. Link: https://bit.ly/3x1yerq

8. IEA (2009) Energy technology transitions for industry: strategies for the next industrial revolution. OECD Publishing, Paris, France. Link: https://bit.ly/3jjFcUi

9. Li X, Yang $\mathrm{Y}, \mathrm{Xu} \mathrm{X}, \mathrm{Xu} \mathrm{C}$, Hong J (2016) Air pollution from polycyclic aromatic hydrocarbons generated by human activities and their health effects in China. Journal of Cleaner Production 112: 1360-1367. Link: https://bit.ly/2SsMQks

10. Wannaz ED, Rodriguez JH, Wolfsberger T, Carreras HA, Pignata ML, et al. (2012) Accumulation of aluminium and physiological status of tree foliage in the vicinity of a large aluminium smelter. Scientific World Journal 2012 865927. Link: https://bit.ly/3dd8NLw

11. Ivanova SV, Ryabchikova IA (2019) Ecological human health risk in aluminum producing areas of Baikal region. In IOP Conference Series: Materials Science and Engineering. IOP Publishing 687: 066013. Link: https://bit.ly/3ji1q9z

12. Tan RB, Khoo HH (2005) An LCA study of a primary aluminum supply chain. Journal of Cleaner Production 13: 607-618. Link: https://bit.ly/3d8Zf3V

13. Liu G, Bangs CE, Müller DB (2013) Stock dynamics and emission pathways of the global aluminium cycle. Nature Climate Change 3: 338-342. Link: https://go.nature.com/3h82xpD

14. Paraskevas D, Kellens K, Van de Voorde A, Dewulf W, Duflou JR (2016) Environmental impact analysis of primary aluminium production at country level. Procedia CIRP 40: 209-213. Link: https://bit.ly/3xSDYDA

15. Norgate TE, Rankin WJ (2001) Greenhouse gas emissions from aluminium production - a life cycle approach. Canada. Link: https://bit.ly/2SsN8I4

16. Hong J, Zhou J, Hong J, Xu X (2012) Environmental and economic life cycle assessment of aluminum-silicon alloys production: a case study in China. Journal of Cleaner Production 24: 11-19. Link: https://bit.ly/3650rBP

17. Ingarao G, Deng Y, Marino R, Di Lorenzo R, Franco AL (2016) Energy and CO2 life cycle inventory issues for aluminum based components: the case study of a high speed train window panel. Journal of Cleaner Production 126: 493-503. Link: https://bit.ly/3vYejrM

18. Rebitzer G, Ekvall T, Frischknecht R, Hunkeler D, Norris G, et al. (2004) Life cycle assessment: Part 1: Framework, goal and scope definition, inventory analysis, and applications. Environ Int 30: 701-720. Link: https://bit.ly/3gQ9Rah

19. Suciati A Goto N (2014) Environmental Impact Assessment of the Development of Primary Aluminium Industry in Indonesia based on MFA and LCA as a Baseline Study to Achieve Sustainable Industry. 3rd International Conference on Environment Energy and Biotechnology IPCBEE, IACSIT Press, Singapore. Link: https://bit.ly/3j8dWbv

Copyright: @ 2021 Abdollahi J, et al. This is an open-access article distributed under the terms of the Creative Commons Attribution License, which permits unrestricted use, distribution, and reproduction in any medium, provided the original author and source are credited.

Citation: Abdollahi J, Emrani N, Chahkandi B, Montazeri A, Gheibi M, at al.(2021) Environmental impact assessment of aluminium production using the life cycle assessment tool and multi-criteria analysis. Ann Environ Sci Toxicol 5(1): 059-066. DOI: https://dx.doi.org/10.17352/aest.000038 